THE POSTGRADUATE

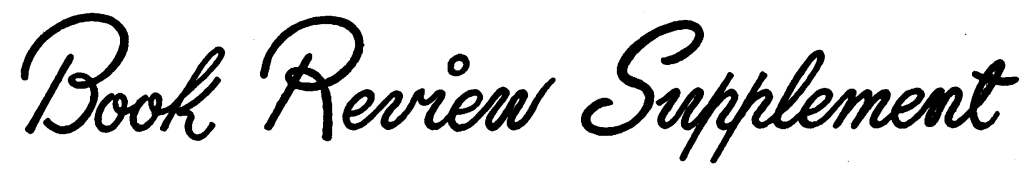

\section{ANATOMY, REGIONAL AND APPLIED}

By R. J. LaST, M.B., B.S., F.R.C.S. Pp. xii + 665, with 309 illustrations, many in colour. London: J. \& A. Churchill Ltd. I954. 55 s.

This book is a cross between a text-book of anatomy and a dissection manual, and is aimed at those who already have a certain knowledge of anatomy.

The author states that he has 'attempted to include in the text all those parts of human anatomy which should occupy a place in the knowledge and in the understanding of the student or general clinician,' and whatever views one may hold on this controversial matter, one cannot fail to admire him for his boldness in so committing himself. It may be noted that the petrosal nerves and the erector spinae muscle are given due attention.

Histology and embryology are dealt with very briefly, and with the main eye towards their practical applications, and the same may be said to apply to the section on the nervous system. The classification of joints given is refreshingly simple, and a considerable amount of recent work on the mechanism of particular joints is included. The section dealing with the innervation of the limbs is excellent, and the simple rules given for remembering the segmental innervation of the musculature and skin will be found very useful.

On the whole, the general impression created by the book is, that it is a well balanced account of regional anatomy with a certain amount of watering down of topographical detail, competently written in a pleasing conversational style, which the postgraduate student revising for a higher examination may find useful to read alongside dissected parts and specimens.

A.S.B.

\section{MEDICAL HISTORY OF THE SECOND WORLD WAR-SURGERY}

Edited by Sir ZACHaRY Cope, B.A., M.D., M.S., F.R.C.S. Pp. xix +772 , with illustrations, many in colour. London: H.M.S.O. 1953. 80 s.

The 2I years which separated the two World Wars brought maturity to many surgical developments, not a few of which had found their birth in the earlier onslaught. Other concepts were still in their infancy in 1939 and the exigencies of the occasion brought them to rapid fruition while creating yet further problems to be met by new advances. To record comprehensively this fascinating story of the surgical evolutions of the Second World War is a stupendous task which has nevertheless been magnificently achieved by $\mathrm{Sir}$ Zachary Cope and his team of authors. It is a success which is no less a tribute to the countless others who worked for the care of the wounded.

It is impossible to single out all the factors which led to improvements in the surgery of the last war, but the excellent blood transfusion service, improved anaesthesia and surgical techniques and the antibiotics all played a considerable part. The clarification of wound treatment together with penicillin, for instance, were largely responsible for the figure of 87 per cent. first intention healing in a large series of head injuries in Normandy. Similarly, the records of a thoracic unit show a steady decrease in the empyema incidence to 7.6 per cent. at the end of the Italian campaign.

Here are faithfully recorded the valuable advances and experience of the specialist units; units such as the plastic teams with their greatly improved results in burns and maxillo-facial injuries or the spinal injuries centres whose remarkable work has been particularly well presented. The nature of the war posed new problems or brought old ones into greater prominence. Thus the crush syndrome, parachute hazards and blast injuries, to mention but a few, exemplify the diversity of subjects covered, references being provided throughout the book for the reader who wishes to delve further.

In the more general field of abdominal surgery, the improvement achieved is well illustrated by the recovery rate of 62 per cent. of all small gut penetrating wounds with or without other injuries; a figure more than twice that of the previous war. Even more remarkable is the fact that these results, attained in the Western Desert, are within I per cent. of those obtained in Britain, a credit not only to the surgical teams in North Africa but to the improved administration with its greater mobility of these teams and better management of casualty evacuation.

It is fitting that there should be a chapter on the courage and tenacity of those who cared for their fellow unfortunates, the prisoners of war, achieving so much under such appalling conditions. Equally 